\title{
Research on the Complex Dynamic Characteristics and RLS Estimation's Influence Based on Price and Service Game
}

\author{
Junhai Ma and Zhanbing Guo \\ College of Economics and Management, Tianjin University, Tianjin 300072, China \\ Correspondence should be addressed to Junhai Ma; mjhtju@aliyun.com and Zhanbing Guo; zhanbinggu0@163.com
}

Received 10 January 2015; Revised 5 May 2015; Accepted 21 May 2015

Academic Editor: Laura Gardini

Copyright (C) 2015 J. Ma and Z. Guo. This is an open access article distributed under the Creative Commons Attribution License, which permits unrestricted use, distribution, and reproduction in any medium, provided the original work is properly cited.

Considering that the real competitions in service market contain two important factors, price and service, we build a dynamical price and service game model and study the complex dynamics of this bivariate game. Some special properties about the adjustment of service are noted by comparing our innovative bivariate game model with previous univariate game model. Besides, we discuss the stabilities of fixed points and compare the price and service game with price game. What is more, the recursive least-squares (RLS) estimation is introduced to substitute naive estimation; then the impacts of RLS estimation are studied by comparing it with naive estimation.

\section{Introduction}

Over the past several decades, bounded rational players' dynamical competitions have attracted quite some attention. Scholars have carried out their researches from multiple angles and have got abundant achievements. Zhang et al. [1] studied the Bertrand model with bounded rational players; they found that adjustment speed can change the stability of the Nash equilibrium point. Agiza and Elsadany [2] investigated the dynamics of a nonlinear discrete-time duopoly output game with heterogeneous players; they indicated that bifurcation, chaos, and other complex phenomena may occur if some parameters are changed. Li et al. [3] studied the impact of delay on the system and found that delay can expand the stable region of Nash equilibrium. Ma and Guo [4] analysed the complex dynamics of a duopoly Cournot game model with heterogeneous players, where one player adopts "one-period look-ahead" behavior. Considering the specific situation in different markets, scholars built the dynamic game models in Chinese cold rolled steel market [5], Chinese property insurance market [6], Chinese 3G telecommunication market [7], and advertising competition market [8]; they studied the stability of Nash equilibrium and showed the influence of adjustment speed on the evolution of dynamic systems. Besides above researches, Ma et al. $[9,10]$ studied the complex characteristics of Cournot-Bertrand mixed model, where one firm sees price as decision variable and one firm sees output as decision variable. Bischi and Naimzada [11] and Fanti et al. [12] studied the global dynamics of dynamical systems.

These studies play important roles for us to understand the dynamical games among limited rational players, but they are based on the assumption that each player has only one decision variable; this assumption limits their applications. In the real market, customers take many things into consideration and firms usually adjust many aspects to meet the heterogeneous needs of customers.

In multifactor markets, the optimal policies for rational decision makers have been studied by many scholars. Matsubayashi and Yamada $[13,14]$ considered a price and quality competition between two firms, in which consumers buy a product in consideration of both its price and its quality level and firms compete with each other in determining their prices and quality levels to maximize their profits. Qian [15] modeled product (or service) demand as a linear function of attributes including price, guaranteed delivery time, service level, or other quality-like performances and proposed a market-based strategy for joint decisions. Dubovik and Janssen [16] considered an oligopolistic market where firms compete in price and quality and consumers are 
heterogeneous in their knowledge of the prices and quality of products; they derived a perfect indicator equilibrium for this setting. In these papers mentioned above, price, quality, and other variables (if exist), as decision variables, are endogenously chosen by firms. There are also many literatures $[17,18]$; they considered the uninformed consumers and investigated firms' policies under price-quality relationship, where the uninformed consumers do not know the real quality of product but see price as a signal of it.

As far as we know, the analysis of the dynamical competition with both bounded rational players and multidecision variables is rare. To fill this gap, in this paper we build a bivariate (price and quality of service) game model based on the fact that price and quality of service are the most vital factors in service market. We assume that consumers, who have different preferences, are well informed about all product characteristics; both price and quality of service are endogenous decision variables for firms; other product characteristics are different between different firms and are unchanged during the competition.

The main contributions are listed as follows. (1) We study the evolution characteristics of bivariate game under different adjustment mechanisms. Some well-known adjustment mechanisms under limited rationality hypothesis contain best reply with naive expectation, adaptive adjustment, and bounded rational adjustment (see $[19,20])$. In this paper, we assume the three adjustment mechanisms mentioned above are adopted by three firms to see their respective evolution characteristics. (2) We analyze the stabilities of the fixed points, study the impacts of different parameters on complex dynamics, and compare the price and service game with price game. (3) We study the impacts of recursive least-squares (RLS) estimation on system. The evolution characteristics of system under RLS (or recursive weighted least-squares) estimation have been studied by $[4,21]$, but they did not investigate the difference between RLS (or recursive weighted least-squares) estimation and naive estimation; in this paper, we study the difference between RLS estimation and naive estimation by comparing their stable regions, basin of attractions, and profits.

The remainder of this paper is organized as follows. In Section 2, the price and service competition model with heterogeneous players is built. The evolution characteristics of heterogeneous players, fixed points' stabilities, complex dynamics features, and the differences between bivariate game and univariate game are discussed in Section 3. In Section 4, the differences between RLS estimation and naive estimation are analyzed. Finally, the conclusion of this paper is provided in Section 5.

\section{Price and Service Competition Model}

We assume there are three players (firms) in the market; they offer similar products and services (firm $i$ offers product $i$ and service $i)$. Let $p_{i}(t)$ denote the price of product $i$ and let $s_{i}(t)$ denote the quality of service offered by firm $i$ at discretetime period $t(t=1,2, \ldots)$. Services, which are free of charge for customers, can be seen as attachment of products; if one customer buys firm $i$ 's product in one period, then he also can enjoy the free service promised by firm $i$ at the beginning of that time period.

We hypothesize that customers have different preferences and they consider $p_{i}$ and $s_{i}$ as well as the average values of the other two firms $\left(p_{k}+p_{j}\right) / 2$ and $\left(s_{k}+s_{j}\right) / 2$ when they decide whether to purchase product $i$ or not. When $p_{i}\left(\right.$ or $\left.\left(s_{k}+s_{j}\right) / 2\right)$ increases, the demand of product $i$ will decrease; on the other hand, if $\left(p_{k}+p_{j}\right) / 2$ (or $\left.s_{i}\right)$ increases, the demand of goods $i$ will rise. The demand of product $i$ at time period $t$ is assumed to be a linear function in this paper:

$$
\begin{aligned}
Q_{i}(t)= & a_{i}-b_{i} p_{i}(t)+d_{i} \frac{p_{j}(t)+p_{k}(t)}{2}+e_{i} s_{i}(t) \\
& -f_{i} \frac{s_{j}(t)+s_{k}(t)}{2}
\end{aligned}
$$

where $i, j, k=1,2,3, i \neq j \neq k$, and $a_{i}, b_{i}, d_{i}, e_{i}, f_{i}>0, b_{i}>d_{i}$, $e_{i}>f_{i} . a_{i}$ can be viewed as the size of market base, which is large enough so that $Q_{i}(t)$ will always be nonnegative; $b_{i}, d_{i}, e_{i}, f_{i}$ denote the impacts of prices or services.

We assume that each firm's marginal cost of further improvement in service rises as service increases and the cost function of each firm at period $t$ takes the form: $C_{i}(t)=$ $c_{i} s_{i}^{2}(t)+h_{i}$, where $c_{i}, h_{i}>0, h_{i}$ represents the fixed cost, and $c_{i}$ is a coefficient connecting $s_{i}^{2}$ and cost.

Therefore, the total profit function of firm $i$ is given by

$$
\begin{aligned}
\pi_{i}= & \left(a_{i}-b_{i} p_{i}+d_{i} \frac{p_{j}+p_{k}}{2}+e_{i} s_{i}-f_{i} \frac{s_{j}+s_{k}}{2}\right) \\
& \cdot\left(p_{i}-c_{i} s_{i}^{2}-h_{i}\right) .
\end{aligned}
$$

The adjustment mechanisms play important roles in the dynamical game; some well-known adjustment mechanisms under limited rationality hypothesis contain best reply with naive expectation, adaptive adjustment, and bounded rational adjustment (see $[19,20])$. Elabbasy et al. [20] considered these adjustment mechanisms in a Cournot game and studied their evolution characteristics and the impacts of different adjustment parameters. In this paper, in order to compare the evolution characteristics of each adjustment mechanism in bivariate game with that in univariate game thoroughly, we consider heterogeneous players instead of homogeneous players; that is, players adopt different adjustment mechanisms. In particular, we extend the model in [20] to bivariate game (price and service); we assume the three adjustment mechanisms mentioned above are adopted by three firms, respectively; this makes it feasible for us to study their respective evolution characteristics and compare these characteristics in bivariate game model with that in univariate game model.

We assume the first player is a bounded rational player; he builds his decisions based on marginal profit (see $[1,2,5$, $6,20,22]$ ); when the marginal profit $\partial \pi_{1} / \partial p_{1}\left(\right.$ or $\left.\partial \pi_{1} / \partial s_{1}\right)$ is positive, he will increase $p_{1}$ (or $s_{1}$ ) in the next time period; on 
the other hand, if marginal profit is negative he will decrease $p_{1}\left(\right.$ or $\left.s_{1}\right)$ in the next time period:

$$
\begin{aligned}
& p_{1}(t+1)=p_{1}(t)+\alpha_{1} p_{1}(t) \frac{\partial \pi_{1}(t)}{\partial p_{1}(t)} \\
& s_{1}(t+1)=s_{1}(t)+\beta_{1} s_{1}(t) \frac{\partial \pi_{1}(t)}{\partial s_{1}(t)}
\end{aligned}
$$

where $\alpha_{1}\left(\alpha_{1}>0\right)$ and $\beta_{1}\left(\beta_{1}>0\right)$ are adjustment parameters (or adjustment speeds); the marginal profits are

$$
\begin{aligned}
& \frac{\partial \pi_{1}}{\partial p_{1}}=a_{1}-b_{1} p_{1}+d_{1} \frac{p_{2}+p_{3}}{2}+e_{1} s_{1}-f_{1} \frac{s_{2}+s_{3}}{2} \\
& \quad-b_{1}\left(p_{1}-c_{1} s_{1}^{2}-h_{1}\right), \\
& \frac{\partial \pi_{1}}{\partial s_{1}}=e_{1}\left(p_{1}-c_{1} s_{1}^{2}-h_{1}\right)-2 c_{1} s_{1}\left(a_{1}-b_{1} p_{1}\right. \\
& \left.\quad+d_{1} \frac{p_{2}+p_{3}}{2}+e_{1} s_{1}-f_{1} \frac{s_{2}+s_{3}}{2}\right) .
\end{aligned}
$$

Let player 2 be a naive player; he assumes his rivals will repeat their last step decisions in the next time period; he makes his decisions based on his assumption and best reply adjustment mechanism (see $[19,20,22])$. His reaction function can be determined by solving the following equation:

$$
\left(p_{i}^{*}, s_{i}^{*}\right)=\arg \max _{\left(p_{i}, s_{i}\right)} \pi_{i}\left(p_{i}, s_{i}, p_{j}, s_{j}, p_{k}, s_{k}\right) .
$$

Then the dynamical adjustment of player 2 is given by

$$
\begin{aligned}
& p_{2}(t+1)=p_{2}^{*}(t), \\
& s_{2}(t+1)=s_{2}^{*}(t) .
\end{aligned}
$$

We assume the third player is an adaptive player; he makes his decisions with considering both last period's decisions and his reaction function (see $[19,20,22])$; hence the dynamical adjustment of player 3 is

$$
\begin{aligned}
& p_{3}(t+1)=\left(1-\alpha_{3}\right) p_{3}(t)+\alpha_{3} p_{3}^{*}(t), \\
& s_{3}(t+1)=\left(1-\beta_{3}\right) s_{3}(t)+\beta_{3} s_{3}^{*}(t),
\end{aligned}
$$

where $\alpha_{3}, \beta_{3} \in(0,1]$ are adjustment parameters.

To get the reaction functions of firms 2 and 3 , we take firm 2 for example. We first look at the first-order condition of (5):

$$
\begin{aligned}
& \frac{\partial \pi_{2}}{\partial p_{2}}=-b_{2}\left(p_{2}-c_{2} s_{2}^{2}-h_{2}\right)+a_{2}-b_{2} p_{2}+\frac{d_{2}\left(p_{1}+p_{3}\right)}{2} \\
& +e_{2} s_{2}-\frac{f_{2}\left(s_{1}+s_{3}\right)}{2}=0 \\
& \frac{\partial \pi_{2}}{\partial s_{2}}=e_{2}\left(p_{2}-c_{2} s_{2}^{2}-h_{2}\right)-2 c_{2} s_{2}\left(a_{2}-b_{2} p_{2}\right. \\
& \left.+\frac{d_{2}\left(p_{1}+p_{3}\right)}{2}+e_{2} s_{2}-\frac{f_{2}\left(s_{1}+s_{3}\right)}{2}\right)=0
\end{aligned}
$$

By solving the first-order condition, we can get $Q_{2}=0$ or $s_{2}=e_{2} / 2 b_{2} c_{2}$. Obviously, player 2 will ensure $Q_{2}>0$ to get a positive profit in the real market, so in the paper we only consider the following solution:

$$
\begin{aligned}
& s_{2}^{*}=\frac{e_{2}}{2 b_{2} c_{2}}, \\
& p_{2}^{*} \\
& =\frac{b_{2} c_{2} s_{2}^{2}+b_{2} h_{2}+a_{2}+d_{2}\left(\left(p_{1}+p_{3}\right) / 2\right)+e_{2} s_{2}-f_{2}\left(\left(s_{1}+s_{3}\right) / 2\right)}{2 b_{2}} .
\end{aligned}
$$

It is easy to prove the Hessian matrix of this solution is negative definite, so it is the optimal solution (reaction function) if it meets the conditions $Q_{2}\left(p_{2}^{*}, s_{2}^{*}\right)>0$ and $\pi_{2}\left(p_{2}^{*}, s_{2}^{*}\right)>0$; in fact, these conditions usually can be satisfied in the real market. The solution of the reaction function of firm 3 is similar to that of firm 2:

$$
\begin{aligned}
& s_{3}^{*}=\frac{e_{3}}{2 b_{3} c_{3}}, \\
& p_{3}^{*} \\
& =\frac{b_{3} c_{3} s_{3}^{2}+b_{3} h_{3}+a_{3}+d_{3}\left(\left(p_{1}+p_{2}\right) / 2\right)+e_{3} s_{3}-f_{3}\left(\left(s_{1}+s_{2}\right) / 2\right)}{2 b_{3}} .
\end{aligned}
$$

Then we can get the price and service dynamical game model:

$$
\begin{aligned}
& p_{1}(t+1)=p_{1}(t)+\alpha_{1} p_{1}(t) \frac{\partial \pi_{1}(t)}{\partial p_{1}(t)}, \\
& s_{1}(t+1)=s_{1}(t)+\beta_{1} s_{1}(t) \frac{\partial \pi_{1}(t)}{\partial s_{1}(t)}, \\
& p_{2}(t+1)=p_{2}^{*}(t), \\
& s_{2}(t+1)=s_{2}^{*}(t), \\
& p_{3}(t+1)=\left(1-\alpha_{3}\right) p_{3}(t)+\alpha_{3} p_{3}^{*}(t), \\
& s_{3}(t+1)=\left(1-\beta_{3}\right) s_{3}(t)+\beta_{3} s_{3}^{*}(t) .
\end{aligned}
$$

\section{Analysis and Numerical Simulation of Bivariate Game}

In this section the evolution characteristics of bivariate game with heterogeneous players, fixed points' stabilities, complex dynamics features, and the differences between bivariate game and univariate game will be discussed.

3.1. The Evolution Characteristics of Heterogeneous Players in Bivariate Game Model. Comparing with the univariate game models with heterogeneous players, where all variables have the same stability (see $[2,20,22,23]$ ), we show some special properties about the bivariate game system (11) by the following remark.

Remark 1. No matter what their initial values are and what the state of system is, the quality of service offered by the player, who uses best reply with naive expectation mechanism, is fixed after one period and the quality of service offered by the player, who uses adaptive adjustment, is convergent. 
Proof. From the expressions of $s_{2}^{*}(t)$ and $s_{3}^{*}(t)$ we can know that both $s_{2}^{*}(t)$ and $s_{3}^{*}(t)$ are constants, so we can get that $s_{2}(t)$ is fixed after one period and $s_{3}(t)$ is always convergent.

Noting that $s_{2}^{*}(t)$ and $s_{3}^{*}(t)$ are constants and the services offered by player 2 and player 3 are convergent, we set $s_{2}^{*}(t)$ and $s_{3}^{*}(t)$ as the initial values of $s_{2}$ and $s_{3}$ respectively to simplify this model. Then the dynamical system can be simplified as

$$
\begin{aligned}
& p_{1}(t+1)=p_{1}(t)+\alpha_{1} p_{1}(t) \frac{\partial \pi_{1}(t)}{\partial p_{1}(t)} \\
& s_{1}(t+1)=s_{1}(t)+\beta_{1} s_{1}(t) \frac{\partial \pi_{1}(t)}{\partial s_{1}(t)} \\
& p_{2}(t+1)=p_{2}^{*}(t), \\
& p_{3}(t+1)=\left(1-\alpha_{3}\right) p_{3}(t)+\alpha_{3} p_{3}^{*}(t) .
\end{aligned}
$$

3.2. Fixed Points and Stability Analysis. In the following part, we will study the fixed points of system (12) and investigate their stabilities. By setting $p_{i}(t+1)=p_{i}(t)$ and $s_{i}(t+1)=$ $s_{i}(t)$, we can get the fixed points of system (12). To simplify the expressions of fixed points and the analyses, one numerical example is utilized in this paper by setting $a_{1}=17, b_{1}=2.0$, $c_{1}=0.22, d_{1}=1.5, e_{1}=1.6, f_{1}=1.1, h_{1}=1.3, a_{2}=14$, $b_{2}=2.2, c_{2}=0.22, d_{2}=1.6, e_{2}=1.7, f_{2}=1.2, h_{2}=1.2$, $a_{3}=16, b_{3}=2.1, c_{3}=0.23, d_{3}=1.55, e_{3}=1.8, f_{3}=1.2$, and $h_{3}=1.1$. Then we can get four nonnegative fixed points $E\left(p_{1}, s_{1,} p_{2}, p_{3}\right)$ :

$$
\begin{aligned}
& E_{1}=(8.3392,1.8182,7.2546,7.9242), \\
& E_{2}=(0,0,5.7016,6.3586), \\
& E_{3}=(7.2754,0,7.3229,8.0002), \\
& E_{4}=(22.3613,9.0412,9.7032,9.7843) .
\end{aligned}
$$

In order to investigate the local stabilities of these fixed points, we assume $J$ is the Jacobian matrix of system (12); then we can get $J$ :

$$
J=\left[\begin{array}{cccc}
J_{11} & \alpha_{1} p_{1}\left(2 b_{1} c_{1} s_{1}+e_{1}\right) & \frac{1}{2} \alpha_{1} p_{1} d_{1} & \frac{1}{2} \alpha_{1} p_{1} d_{1} \\
\beta_{1} s_{1}\left(2 b_{1} c_{1} s_{1}+e_{1}\right) & J_{22} & -\beta_{1} c_{1} d_{1} s_{1}^{2} & -\beta_{1} c_{1} d_{1} s_{1}^{2} \\
\frac{d_{2}}{4 b_{2}} & -\frac{f_{2}}{4 b_{2}} & 0 & \frac{d_{2}}{4 b_{2}} \\
\frac{d_{3}}{4 b_{3}} & -\frac{f_{3}}{4 b_{3}} & \frac{d_{3}}{4 b_{3}} & 1-\alpha_{3}
\end{array}\right],
$$

where $J_{11}=1+\alpha_{1}\left(\partial \pi_{1} / \partial p_{1}-2 b_{1} p_{1}\right)$ and

$$
\begin{aligned}
J_{22} & =1+\beta_{1} \frac{\partial \pi_{1}}{\partial s_{1}}-2 \beta_{1} s_{1} c_{1}\left(2 e_{1} s_{1}+a_{1}-b_{1} p_{1}\right. \\
& \left.+d_{1} \frac{p_{2}+p_{3}}{2}+e_{1} s_{1}-f_{1} \frac{s_{2}+s_{3}}{2}\right) .
\end{aligned}
$$

Further analyses about these fixed points give us some conclusions about $E_{2}, E_{3}$, and $E_{4}$.

Remark 2. The fixed points $E_{2}, E_{3}$, and $E_{4}$ of system (12) are unstable fixed points.

Proof. According to the stability condition for fixed point, The modules of all characters' roots should be $<1$ (see [24]). At point $E_{2}$, its corresponding Jacobian matrix is

$$
\left[\begin{array}{cccc}
J_{11} & 0 & 0 & 0 \\
0 & J_{22} & 0 & 0 \\
\frac{d_{2}}{4 b_{2}} & -\frac{f_{2}}{4 b_{2}} & 0 & \frac{d_{2}}{4 b_{2}} \\
\frac{d_{3}}{4 b_{3}} & -\frac{f_{3}}{4 b_{3}} & \frac{d_{3}}{4 b_{3}} & 1-\alpha_{3}
\end{array}\right],
$$

where $J_{11}=1+\alpha_{1}\left[b_{1} h_{1}+Q_{1}(t)\right], J_{22}=1-\beta_{1} e_{1} h_{1}$. We can get one eigenvalue of this Jacobian matrix: $\lambda=1+\alpha_{1}\left[b_{1} h_{1}+\right.$
$\left.Q_{1}(t)\right]$. For $\alpha_{1}, b_{1}, h_{1}>0$ and $Q_{1}(t) \geq 0$, we can get $\lambda>1$, so $E_{2}$ is unstable. In a similar way, we can get the Jacobian matrix at point $E_{3}$ has one eigenvalue: $\lambda=1+\beta_{1} e_{1}\left(p_{1}-h_{1}\right)$; because $\beta_{1}, e_{1}>0, p_{1}>h_{1}$, we can know $E_{3}$ is unstable for $\lambda>1$. It is also easy to understand that $E_{4}$ is unstable; because if we assume a point $(22.3613,9.0412+\varepsilon, 9.7032,9.7843)$, which is sufficiently close to $E_{4}$ (where $\varepsilon>0$ ), then we have $\partial \pi_{1} / \partial s_{1} \approx$ $7.44 \gg 0$, so $s_{1}(t+1)>s_{1}(t)>9.0412$ and $s_{1}(t+1)$ gets farther away from 9.0412. Above all $E_{2}, E_{3}$, and $E_{4}$ are unstable fixed points. This completes the proof of this remark.

$E_{1}$ is the Nash equilibrium point of system (12), which satisfies $\partial \pi_{1} / \partial p_{1}=0$ and $\partial \pi_{1} / \partial s_{1}=0$; its stability can be judged by Jury stability criterion. We assume the characteristic equation of $J$ is $f(\lambda)=\lambda^{4}+A \lambda^{3}+B \lambda^{2}+C \lambda+D=$ 0 . According to Jury stability criterion (see [6]), the sufficient condition for asymptotic stabilization of $E_{1}$ is

$$
\begin{aligned}
& 1+A+B+C+D>0, \\
& 1-A+B-C+D>0, \\
& 1-D^{2}>0 \\
& \left(1-D^{2}\right)^{2}-(C-A D)^{2}>0
\end{aligned}
$$




$$
\begin{aligned}
& {\left[\left(1-D^{2}\right)^{2}-(C-A D)^{2}\right]^{2}} \\
& \quad-\left[B(1-D)^{3}-(A-C D)(C-A D)\right]^{2}>0 .
\end{aligned}
$$

Jury stability criterion means that if condition (17) holds, $E_{1}$ is an asymptotically stable fixed point; these points in the small neighborhood of $E_{1}$ will converge to $E_{1}$ after a few periods; if condition (17) does not hold, $E_{1}$ may be not asymptotically stable; then bifurcation or even chaos may happen.

3.3. The Complex Dynamics Features of System (12). The dynamical behaviors of this complicated system are hard to be studied by analytical method because of the complicated expressions. In order to obtain a deeper understanding of this bivariate dynamical system, some dynamic behaviors of system (12) with the given parameter values are simulated in the following text.

Figures 1 and 2 show the stable region of adjustment parameters; from them we can see that system (12) is asymptotically stable when bounded rational player's adjustment speeds are small; with the increase of either $\alpha_{1}$ or $\beta_{1}$, system (12) will lose its stability; however, the influence of $\alpha_{3}$ relies on $\alpha_{1}$ and $\beta_{1}$; the value of $\alpha_{3}$ influences system's stability only when $\alpha_{1}$ and $\beta_{1}$ are close to the boundary of their stable region.

Figure 3 shows system's bifurcation diagram of prices and the corresponding maximal Lyapunov exponent with respect to $\alpha_{1}$ when $\beta_{1}=0.02, \alpha_{3}=0.5$. Figure 5 shows system's bifurcation diagram of prices and the corresponding maximal Lyapunov exponent with respect to $\beta_{1}$ when $\alpha_{1}=0.02, \alpha_{3}=$ 0.5 . The maximal Lyapunov exponent is used to test chaos; system is in chaos when it has positive maximal Lyapunov exponent. We can see from Figures 3 and 5 that the Nash equilibrium point is locally stable when the values of $\alpha_{1}$ and $\beta_{1}$ are small; the increase of price or service adjustment speed of the bounded rational player will lead to the appearance of bifurcation and chaos. What is more, Figures 4 and 6 give the strange attractors, which show the finial states of player 1 in different situations.

Figure 7 shows system's bifurcation diagrams of prices with respect to the parameter $\alpha_{3}$ with different $\alpha_{1}$ and $\beta_{1}$. From Figure 7, we can see that the influence of $\alpha_{3}$ on the system relies on the values of $\alpha_{1}$ and $\beta_{1}$; this is consistent with Figures 1 and 2 .

From the bifurcation diagrams and attractors showed above, we can know that different kinds of adjustment parameters have different impacts on the system. A big value of $\alpha_{1}$ or a big value of $\beta_{1}$ can lead to the appearance of bifurcation and chaos, but two situations have different attractors. The influence of $\alpha_{3}$ on the system relies on $\alpha_{1}$ and $\beta_{1} ; \alpha_{3}$ has no influence on system when $\alpha_{1}$ and $\beta_{1}$ are small; $\alpha_{3}$ influences system's stability only when $\alpha_{1}$ and $\beta_{1}$ are close to the boundary of their stable region.

3.4. Price and Service Game versus Price Game. In this section we will compare price and service game with price game; we set $s_{1}=1.8182$ as the initial value of service to make them

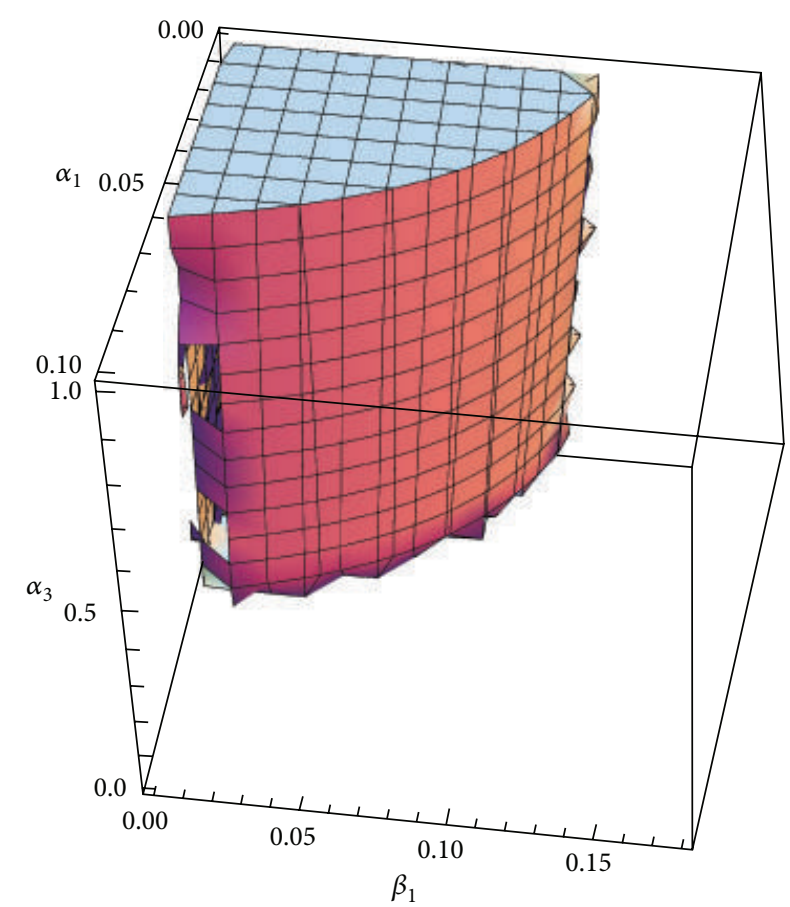

Figure 1: The 3D stable region of $\left(\alpha_{1}, \beta_{1}, \alpha_{3}\right)$.

comparable, because then price game has same equilibrium point with price and service game.

Figure 8 shows the bifurcation diagrams of $p_{1}$ and the corresponding maximal Lyapunov exponents with respect to $\alpha_{1}$ when $\alpha_{3}=0.5$, where blue orbit represents the price game $\left(\beta_{1}=0\right)$ and red orbit represents the price and service game $\left(\beta_{1}=0.02\right)$. We can see from Figure 8 that the stable region of price adjustment speed in price and service game is smaller than that in price game, but the appearance of chaos is delayed. Figure 9 shows the average profits in both price game and price and service game; we can know that player 1's profit in price game is larger than (or is equal to) that in price and service game when $\alpha_{1}$ is small, but with the increase of $\alpha_{1}$, no one is always larger than the other one; price and service game brings more profit when chaos is serious.

We can know that price and service game will reduce the stable region of price adjustment parameter but can delay the appearance of chaos compared with price game; what is more, if the initial service is its equilibrium value, which one can bring more profit depends on the value of price adjustment parameter.

\section{The Influence of RLS Estimation}

Recursive least-square algorithm is a popular and practical algorithm used extensively in signal processing, communications, and control (see [25]). It can reduce the computation complexity of the conventional least-squares method and is usually implemented in a recursive manner. In [21], one estimation was carried out by using linear regression and recursive weighted least-squares method. Simulation results showed that the estimation errors converge to 0 after just 


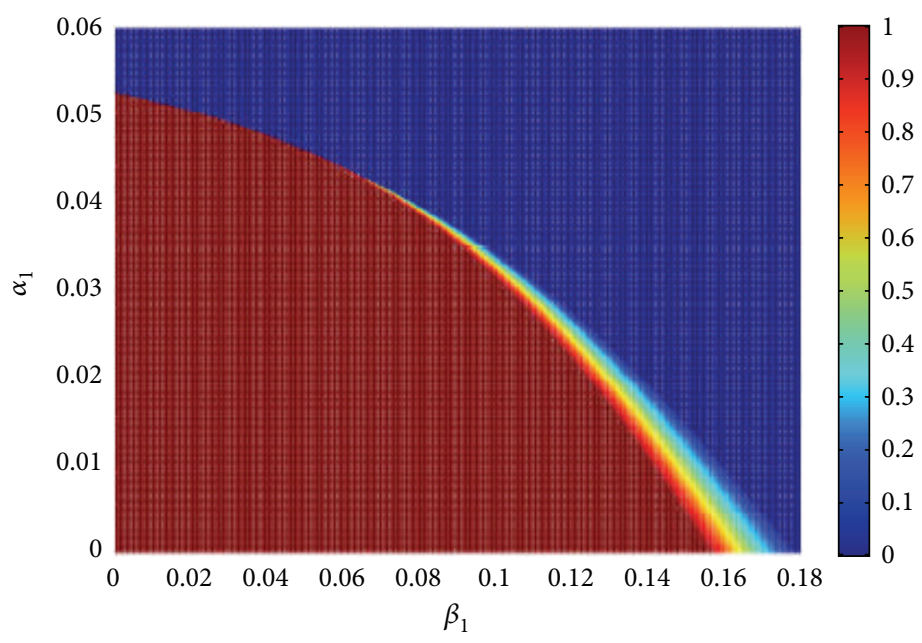

FIGURE 2: The projection of Figure 1 in the $\left(\beta_{1}, \alpha_{1}\right)$ plane.

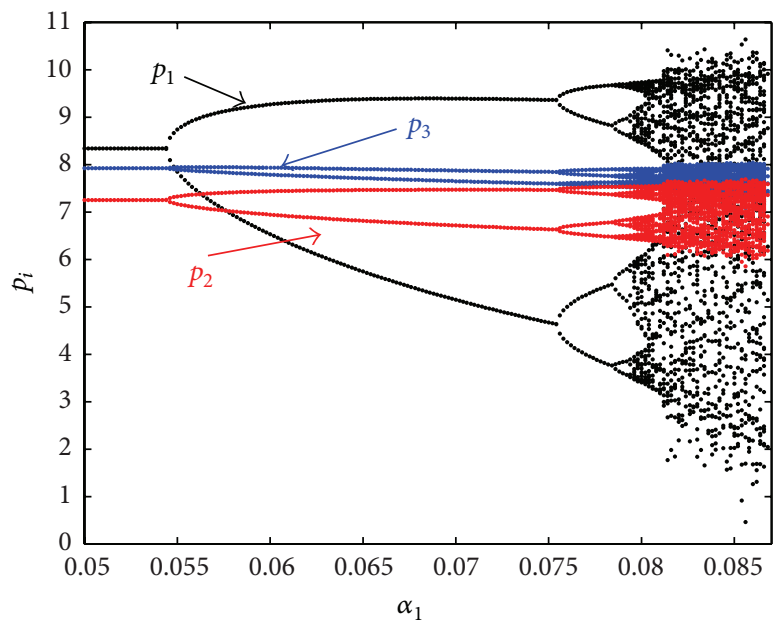

(a)

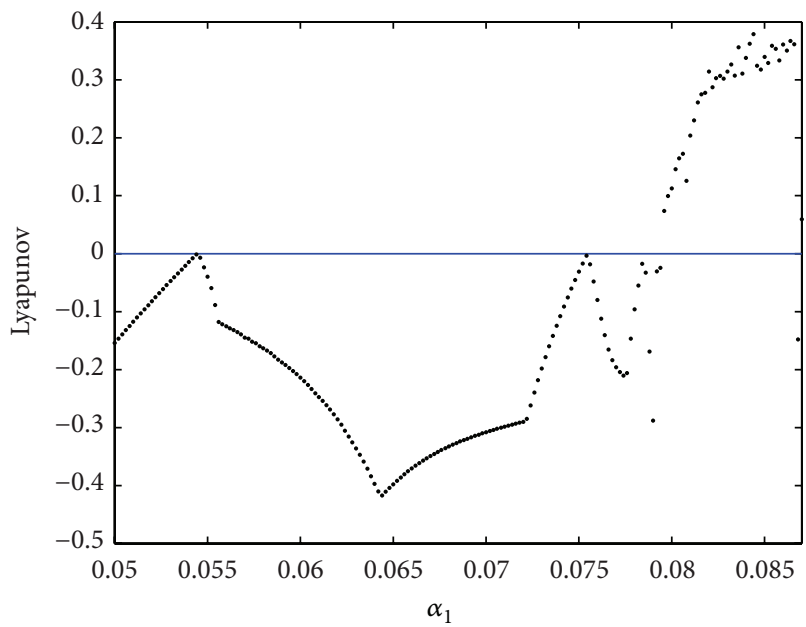

(b)

FIGURE 3: Bifurcation diagram of prices (a) and corresponding maximal Lyapunov exponent (b) with respect to $\alpha_{1}$ when $\beta_{1}=0.02, \alpha_{3}=0.5$.

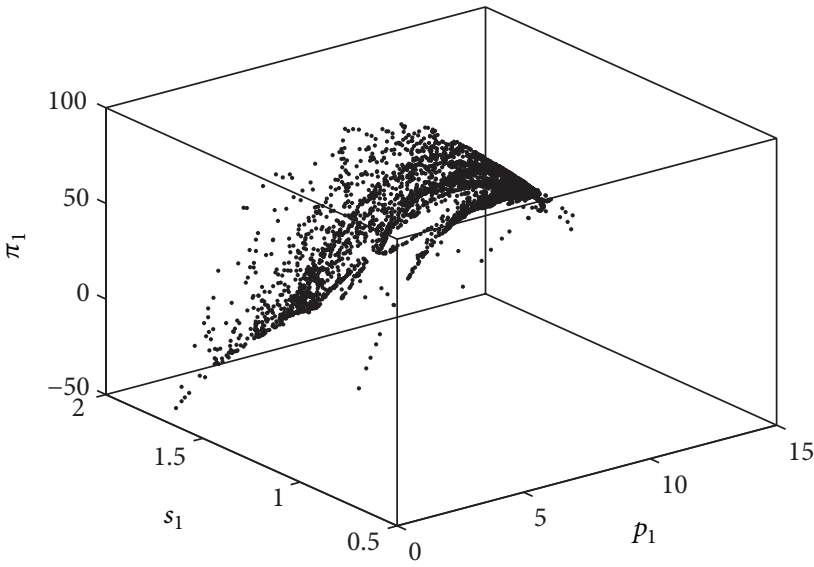

Figure 4: Strange attractor of system (12) when $\alpha_{1}=0.085, \beta_{1}=$ 0.02 , and $\alpha_{3}=0.5$. a few periods. In [4] the complex dynamics of game with RLS estimation is studied, but the difference between RLS estimation and naive estimation is not investigated. In the following part, we assume that player 2 uses RLS estimation instead of naive estimation, compared with naive estimation; the impact of RLS estimation on stable region of parameters and profit and basin of attractions will be analyzed.

We suppose that the second player uses the following models to estimate the other players' behaviors:

$$
\begin{aligned}
& \widehat{p}_{i}(t+1)=x_{i}^{T}(t) \cdot \widehat{\theta}_{i}(t), \quad i=1,3, \\
& \widehat{s}_{1}(t+1)=x_{2}^{T}(t) \cdot \widehat{\theta}_{2}(t),
\end{aligned}
$$

where $x_{i}$ denotes the regression vector and $\widehat{\theta}_{i}$ denotes parameter estimate vector. According to the profit functions and 


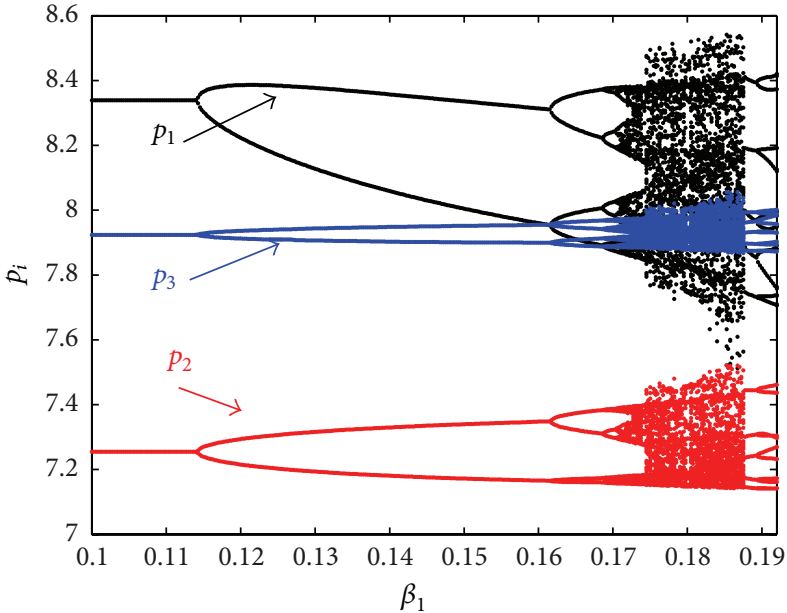

(a)

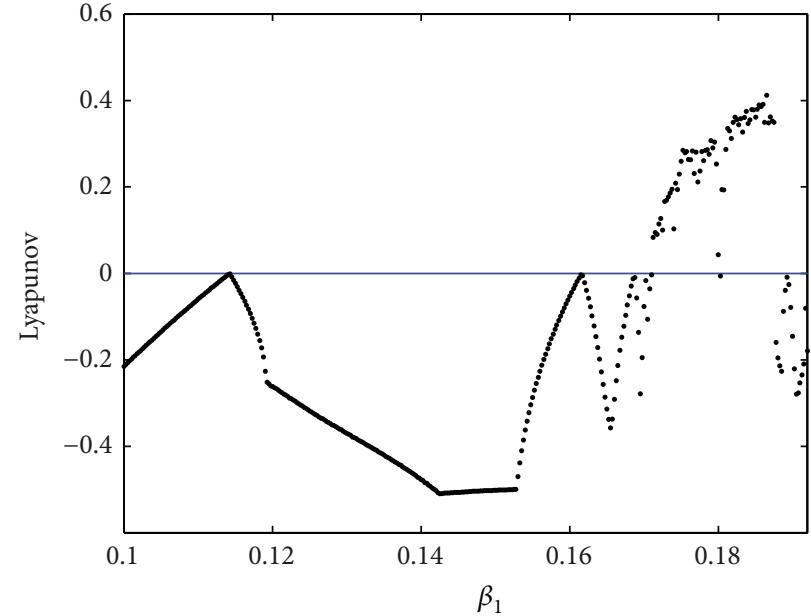

(b)

FIGURE 5: Bifurcation diagram of prices (a) and corresponding maximal Lyapunov exponent (b) with respect to $\beta_{1}$ when $\alpha_{1}=0.02, \alpha_{3}=0.5$.

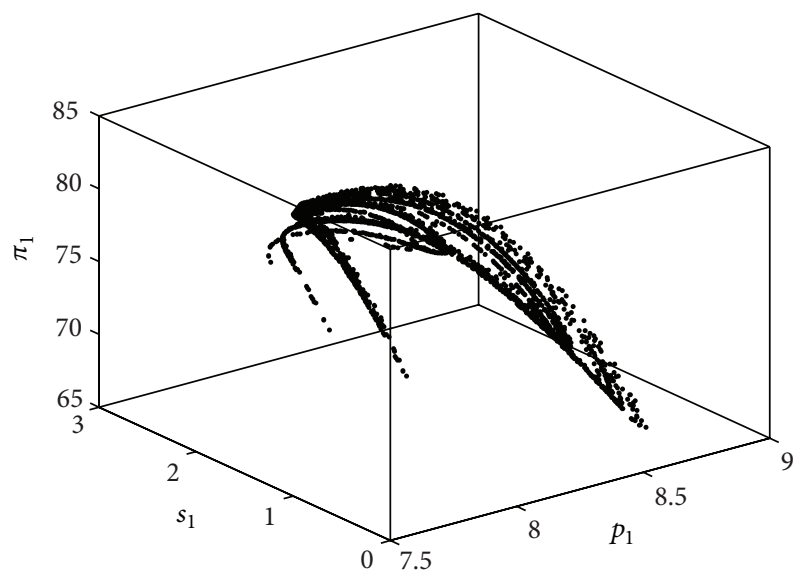

FIGURE 6: Strange attractor of system (12) when $\alpha_{1}=0.02, \alpha_{3}=0.5$, and $\beta_{1}=0.185$.

the decision-making strategies of player 1 and player 3 , we set $x_{i}$ and $\widehat{\theta}_{i}$ as the following forms:

$$
\begin{aligned}
& x_{1}^{T}(t)=\left[1, p_{1}(t), p_{2}(t), p_{3}(t), s_{1}(t), p_{1}^{2}(t), p_{1}(t)\right. \\
& \left.\cdot p_{2}(t), p_{1}(t) p_{3}(t), p_{1}(t) s_{1}^{2}(t)\right]^{T}, \\
& x_{2}^{T}(t)=\left[1, p_{1}(t), p_{2}(t), p_{3}(t), s_{1}(t), s_{1}(t) p_{1}(t),\right. \\
& \left.s_{1}(t) p_{2}(t), s_{1}(t) p_{3}(t), s_{1}^{2}(t)\right]^{T}, \\
& x_{3}^{T}(t)=\left[1, p_{1}(t), p_{2}(t), p_{3}(t), s_{1}(t), p_{1}(t) p_{3}(t),\right. \\
& \left.p_{2}(t) p_{3}(t), p_{3}^{2}(t), p_{3}(t) s_{1}^{2}(t)\right]^{T}, \\
& \widehat{\theta}_{i}(t)=\left[\widehat{\theta}_{i 1}(t), \widehat{\theta}_{i 2}(t), \widehat{\theta}_{i 3}(t), \widehat{\theta}_{i 4}(t), \widehat{\theta}_{i 5}(t), \widehat{\theta}_{i 6}(t),\right. \\
& \left.\widehat{\theta}_{i 7}(t), \widehat{\theta}_{i 8}(t), \widehat{\theta}_{i 9}(t)\right], \quad i=1,2,3 .
\end{aligned}
$$

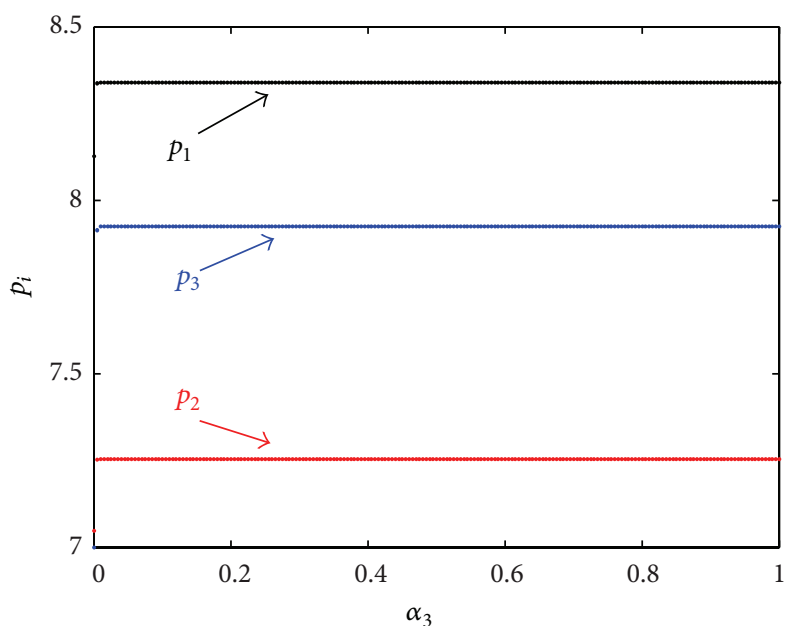

(a)

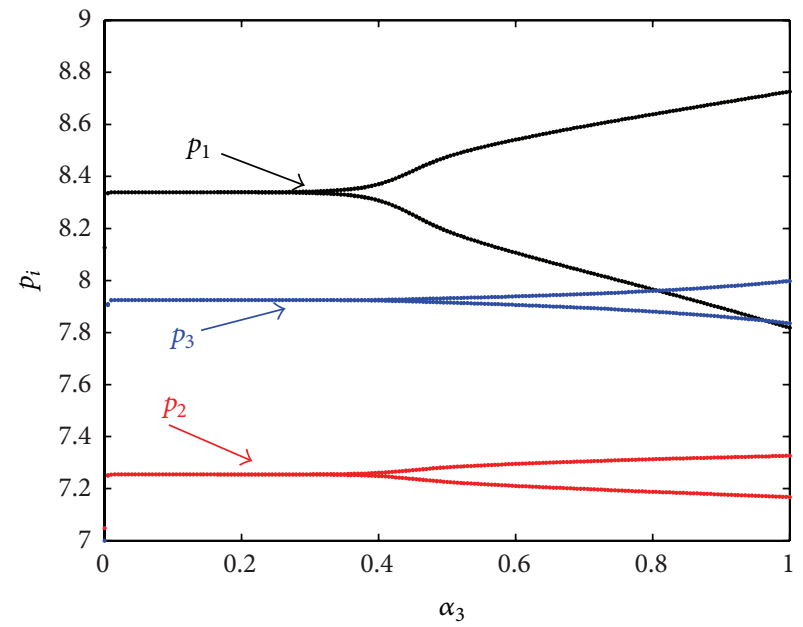

(b)

FIGURE 7: Bifurcation diagram of prices with respect to $\alpha_{3}$ when (a) $\alpha_{1}=0.02, \beta_{1}=0.02$ and (b) $\alpha_{1}=0.05, \beta_{1}=0.043$. 


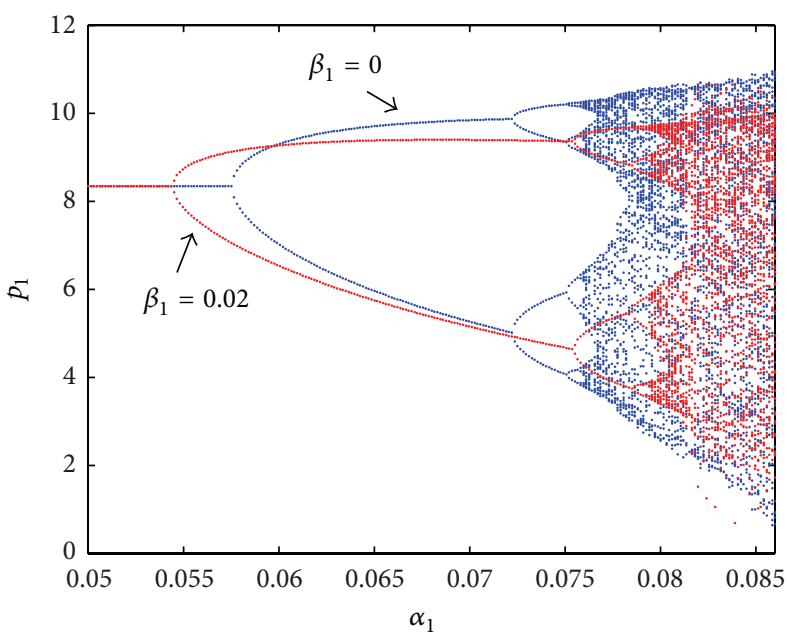

(a)

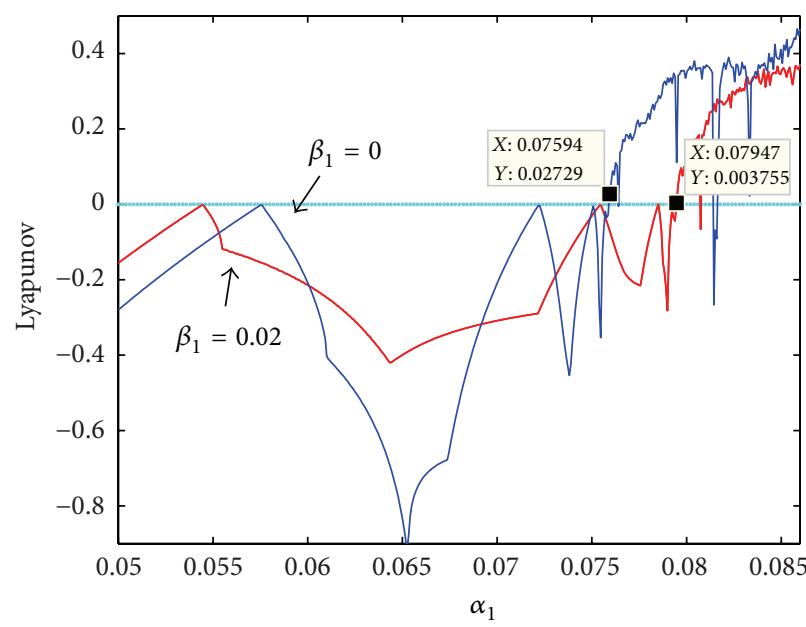

(b)

FIGURE 8: Bifurcation diagram of prices (a) and corresponding maximal Lyapunov exponent (b) with respect to $\alpha_{1}$ when $\alpha_{3}=0.5$.

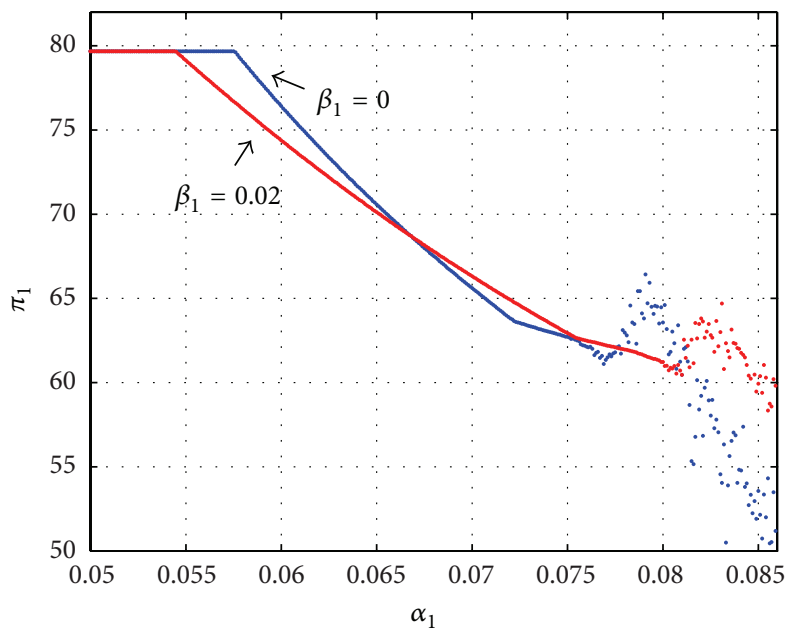

FIGURE 9: The changes of average profit of firm 1 with respect to $\alpha_{1}$ when $\alpha_{3}=0.5$.

We define $\varepsilon_{i}(t)$ as predicting error at time period $t$; then $\varepsilon_{i}(t)$ equals

$$
\begin{aligned}
\varepsilon_{i}(t) & =p_{i}(t)-\widehat{p}_{i}(t), \quad i=1,3, \\
\varepsilon_{2}(t) & =s_{1}(t)-\widehat{s}_{1}(t) .
\end{aligned}
$$

The parameter estimate vector update law under RLS algorithm is

$$
\widehat{\theta}_{i}(t+1)=\widehat{\theta}_{i}(t)+K_{i}(t) x_{i}(t) \varepsilon_{i}(t)
$$

where $K_{i}(t)$ is defined as $K_{i}(t)=P_{i}(t) x_{i}(t) /(1+$ $\left.x_{i}^{T}(t) P_{i}(t) x_{i}(t)\right)$ and $P_{i}(t+1)$ is defined as

$$
P_{i}(t+1)=\left[I-K_{i}(t) x_{i}(t)\right] P_{i}(t) .
$$

To start the RLS algorithm, we should give initial values to $\widehat{\theta}_{i}(1)$ and $P_{i}(1)$. We set the initial value of $\widehat{\theta}_{i}(1)$ as a small vector, for example, $\widehat{\theta}_{i}(1)=[1,1,1,1,1,1,1,1] * 0.02$, and set $P_{i}(1)=r I_{n}$, where $I_{n}$ represents an $n * n$ identity matrix and $r$ is a large positive number. Then the decision-making strategy of player 2 with RLS estimation is

$$
p_{2}(t+1)=\frac{b_{2} c_{2} s_{2}^{2}+b_{2} h_{2}+a_{2}+d_{2}\left(\left(\widehat{p}_{1}(t+1)+\widehat{p}_{3}(t+1)\right) / 2\right)+e_{2} s_{2}-f_{2}\left(\left(s_{3}+\widehat{s}_{1}(t+1)\right) / 2\right)}{2 b_{2}},
$$




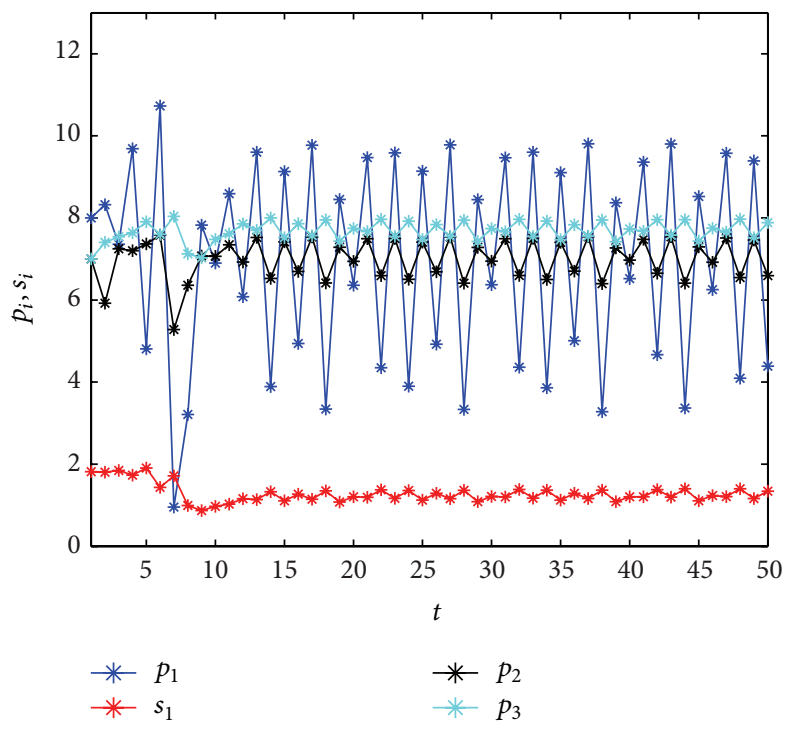

Figure 10: The orbits of $p_{1}, s_{1}, p_{2}$, and $p_{3}$ of system (24) when $\alpha_{1}=0.085, \beta_{1}=0.02$, and $\alpha_{3}=0.5$.

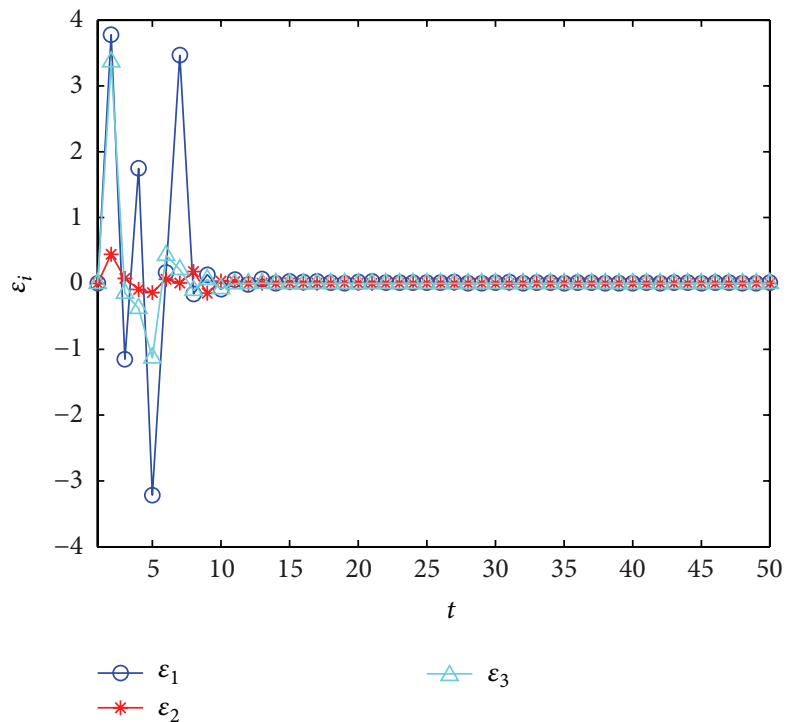

FIGURE 11: Estimation errors of player 2 when $\alpha_{1}=0.085, \beta_{1}=0.02$, and $\alpha_{3}=0.5$.

where $s_{2}=s_{2}^{*}(t)$ and $s_{3}=s_{3}^{*}(t)$. Inserting (23) into system (12) and substituting naive estimation, we get the equations of the new system, where the second player makes decision based on RLS estimation:

$$
\begin{aligned}
& p_{1}(t+1)=p_{1}(t)+\alpha_{1} p_{1}(t) \frac{\partial \pi_{1}(t)}{\partial p_{1}(t)}, \\
& s_{1}(t+1)=s_{1}(t)+\beta_{1} s_{1}(t) \frac{\partial \pi_{1}(t)}{\partial s_{1}(t)}, \\
& p_{2}(t+1)=\frac{b_{2} c_{2} s_{2}^{2}+b_{2} h_{2}+a_{2}+d_{2}\left(\left(\widehat{p}_{1}(t+1)+\widehat{p}_{3}(t+1)\right) / 2\right)+e_{2} s_{2}-f_{2}\left(\left(s_{3}+\widehat{s}_{1}(t+1)\right) / 2\right)}{2 b_{2}}, \\
& p_{3}(t+1)=\left(1-\alpha_{3}\right) p_{3}(t)+\alpha_{3} p_{3}^{*}(t) .
\end{aligned}
$$




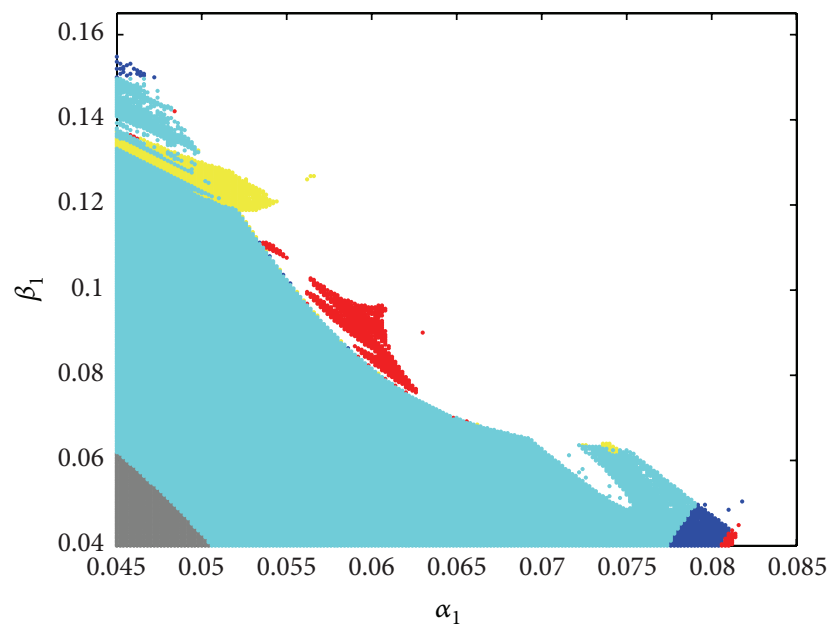

- 6

- 8

(a)

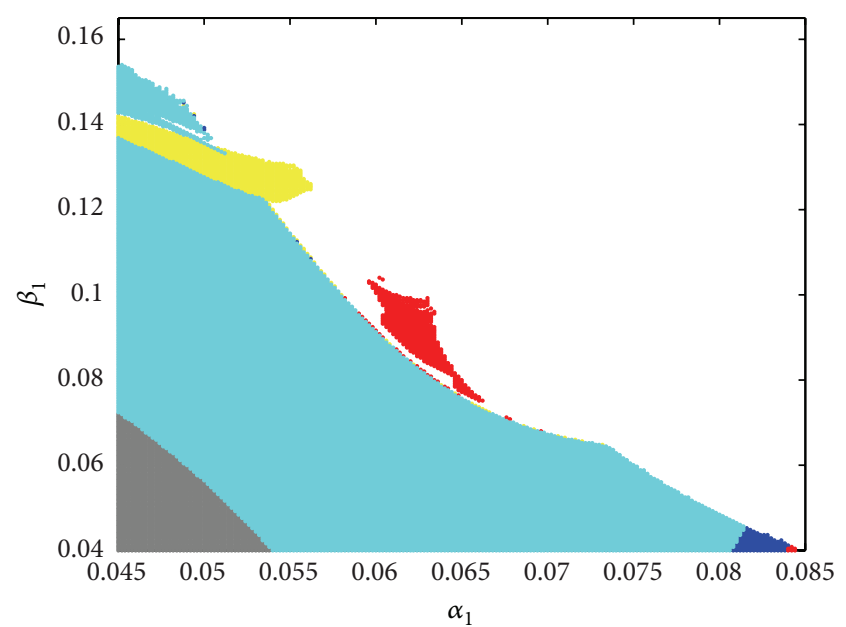

- 6

- 8

(b)

Figure 12: Parameter basin plots in the $\left(\alpha_{1}, \beta_{1}\right)$ plane when $\alpha_{3}=0.5$ : (a) system (12); (b) system (24), where: period-1 (grey), period-2 (cyan), period-4 (blue), period-6 (yellow), period-8 (red), more than 8 (white).

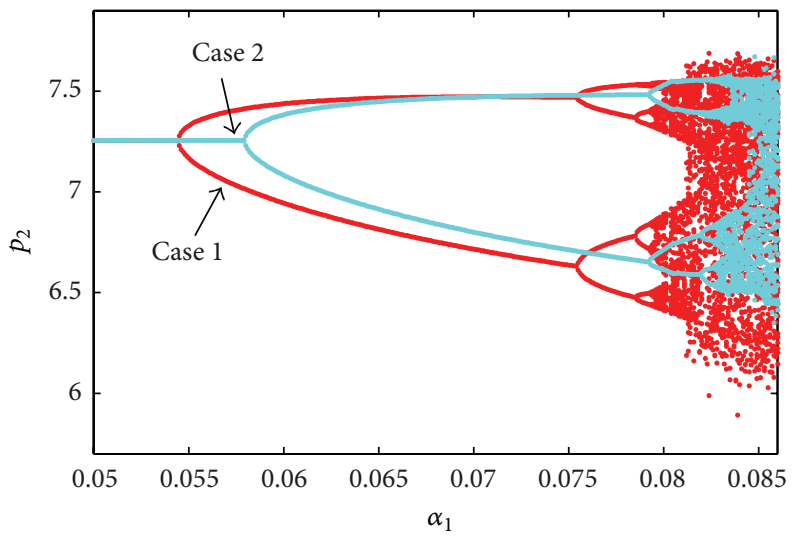

FIGURE 13: Bifurcation diagram of $p_{2}$ with respect to $\alpha_{1}$ when $\beta_{1}=0.02, \alpha_{3}=0.5$, case 1: $p_{2}$ in system (12), case 2: $p_{2}$ in system (24).

In order to see the performance of the RLS algorithm, we set $\alpha_{1}=0.085, \beta_{1}=0.02$, and $\alpha_{3}=0.5$ and depict the orbits and estimation errors of the RLS estimation. Figure 10 shows the orbits of $p_{1}, s_{1}, p_{2}$, and $p_{3}$; Figure 11 gives the estimation errors of player 2. From them we can know that the RLS estimation is accurate and even system (24) is in chaos.

Figure 12 shows the parameter basin plots in the $\left(\alpha_{1}, \beta_{1}\right)$ plane by setting $\alpha_{3}=0.5$, where different periods are depicted in the legend. Comparing with naive estimation, we can know that RLS estimation can expand stable region in parameter plane and postpone the appearance of long-time cycles; that is to say, RLS estimation is beneficial to system stability.

Figure 13 shows the bifurcation diagrams of $p_{2}$ with respect to $\alpha_{1}$ when $\beta_{1}=0.02, \alpha_{3}=0.5$ in two cases: case 1 is the bifurcation diagram of $p_{2}$ in system (12); case 2 is the bifurcation diagram of $p_{2}$ in system (24), where player 2 applies naive estimation in system (12) and applies RLS estimation in system (24); the initial states of case 1 and case 2 are same and in the neighborhood of the Nash equilibrium point. Comparing case 2 with case 1 , we can get the conclusion that the RLS estimation can expand the stable region and postpone the appearance of bifurcation, which are consistent with Figure 12; what is more, we can also know that RLS estimation also can postpone the appearance of chaos. Figure 14 proves this from the other point of view by giving the orbits of $p_{2}$. We can see the orbit of $p_{2}$ is chaotic in (a) when player 2 adopts naive estimation, but it turns to period4 in (b) after player 2 adopts the RLS estimation.

Now, we will study the influence of RLS estimation on profit to see whether adopting RLS estimation is better than adopting naive estimation. Figure 15 shows average profits of player 2 in system (12) (case 1) and system (24) (case 2) 


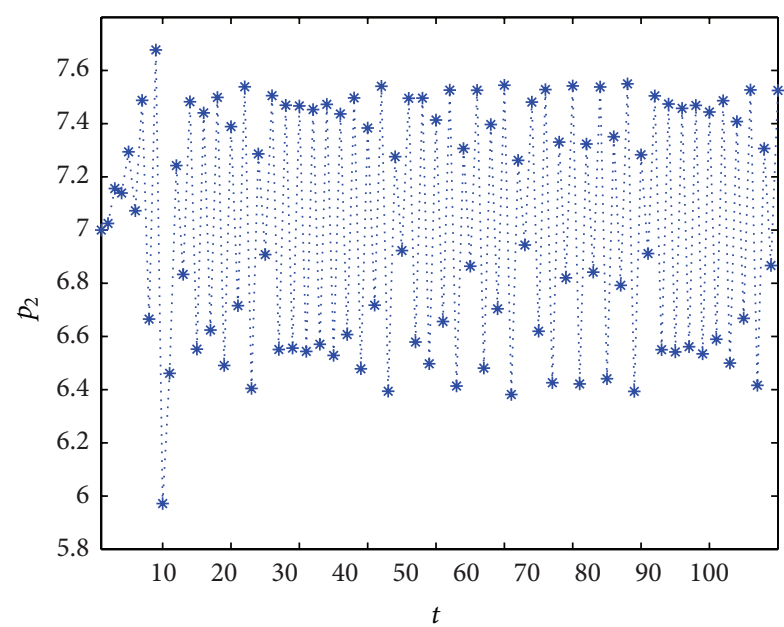

(a)

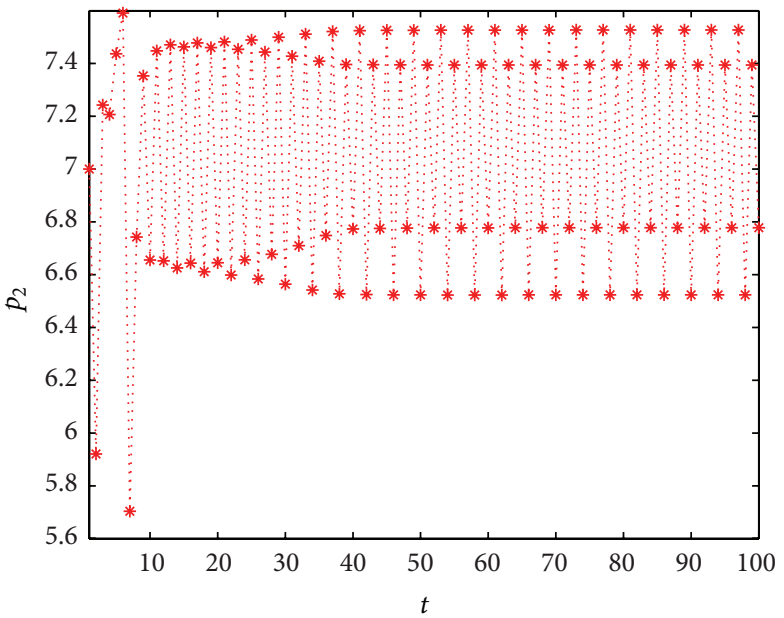

(b)

FIGURE 14: The orbit of $p_{2}$ when $\alpha_{1}=0.081, \beta_{1}=0.02$, and $\alpha_{3}=0.5$ : (a) system (12); (b) system (24).

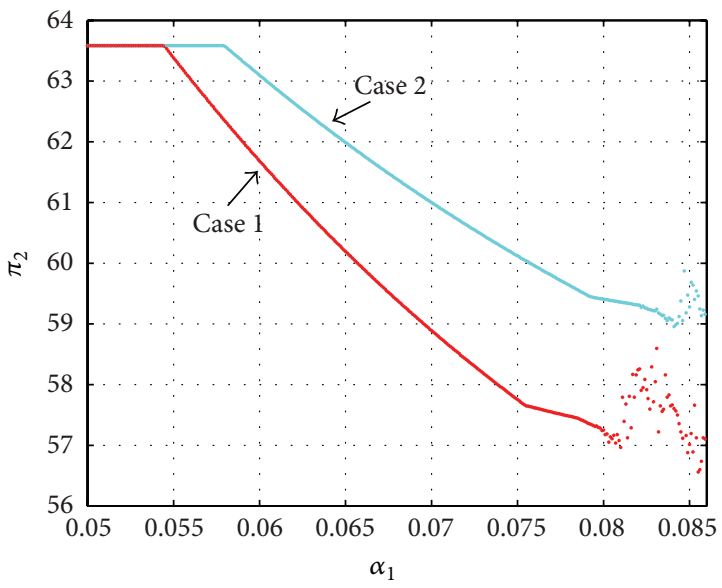

(a)

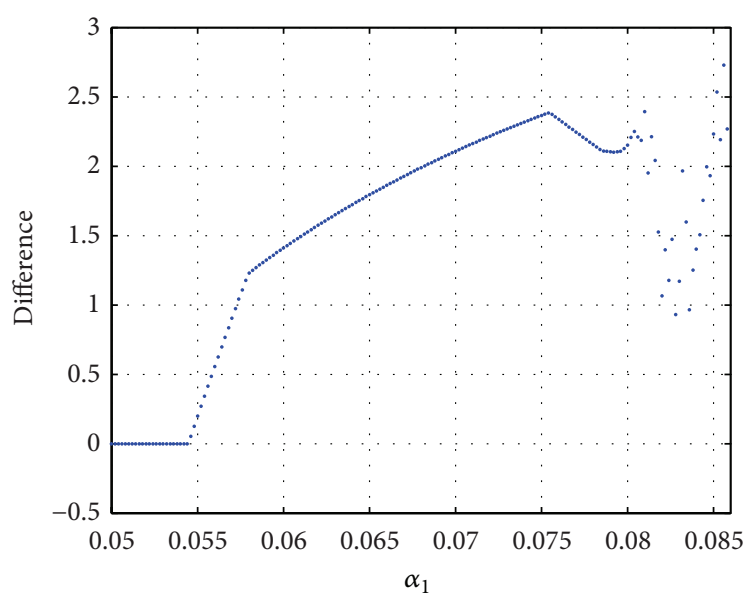

(b)

FIGURE 15: The changes of average profit of firm 2 (a) and their difference (b) with respect to $\alpha_{1}$ when $\beta_{1}=0.02, \alpha_{3}=0.5$, case $1: \pi_{2}$ in system (12), case $2: \pi_{2}$ in system (24).

and gives their difference. From Figure 15 we can get that player 2 has the same profits in two cases if both systems are stable, but player 2 can get more profit in case 2 than in case 1 when system (12) loses its stability. What is more, Figure 15(b) shows the value of adopting RLS estimation compared with naive estimation; if there is an extra cost for adopting RLS estimation, then whether a firm should adopt RLS estimation can be got by comparing its value and its cost.

The basin of attractions of Nash equilibrium point in $\left(p_{1}, s_{1}\right)$ plane is showed in Figure 16 by setting the initial conditions $p_{2}=7.2546, p_{3}=7.9242, \alpha_{1}=0.05, \beta_{1}=$ 0.04 , and $\alpha_{3}=0.5$, where Figure 16(a) corresponds to system (12) and Figure 16(b) corresponds to system (24). From Figure 16 we can see that the basin of attractions of the Nash equilibrium point in system (12) and system (24) is almost same. We can know that although RLS estimation can influence the stable region of parameters, it almost cannot change the basin of attractions of the Nash equilibrium point; that is to say, the RLS estimation cannot expand the basin of Nash equilibrium point.

Above all, we can know that, compared with naive estimation, the stable region of adjustment parameter is expanded if player 2 adopts RLS estimation and adopting RLS estimation can increase player 2's profit if system with naive estimation is unstable; however, the RLS estimation almost cannot change the basin of attractions of Nash equilibrium.

\section{Conclusion}

In this paper, we put forward a price and service competition model with heterogeneous players. We find that the service offered by adaptive player is always convergent; the player, using best reply with naive expectation mechanism, offers fixed service after one period. What is more, the stabilities of 


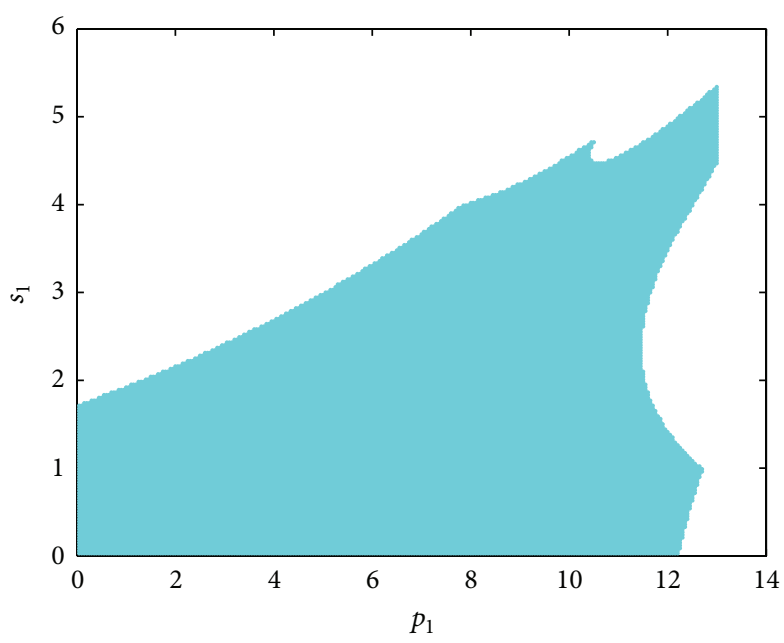

(a)

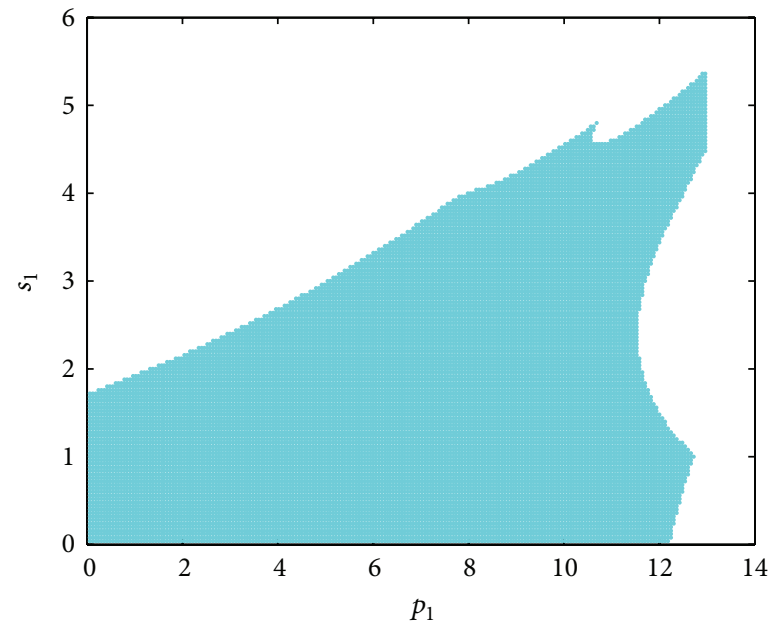

(b)

FIGURE 16: Basin of attractions in $\left(p_{1}, s_{1}\right)$ plane: (a) system (12); (b) system (24).

fixed points, complex dynamics features, and the differences between bivariate game and univariate game are also analyzed in detail. Results of simulation show that bifurcation and chaos may happen in this competition when adjustment parameters change, different adjustment parameters have different impacts on this system, and, compared with price game, price and service game will reduce the stable region of price adjustment parameter but can delay the appearance of chaos. Compared with naive estimation, RLS estimation can expand the stable region of adjustment parameters and increases firm's profit when system with naive estimation is unstable, but RLS estimation cannot expand the basin of attractions of Nash equilibrium point.

\section{Conflict of Interests}

The authors declare that there is no conflict of interests regarding the publication of this paper.

\section{Acknowledgments}

The authors thank the reviewers for their careful reading and providing some pertinent suggestions. The research was supported by the National Natural Science Foundation of China (no. 61273231), Doctoral Fund of Ministry of Education of China (Grant no. 20130032110073), and Tianjin University Innovation Fund.

\section{References}

[1] J. Zhang, Q. Da, and Y. Wang, "The dynamics of bertrand model with bounded rationality," Chaos, Solitons \& Fractals, vol. 39, no. 5, pp. 2048-2055, 2009.

[2] H. N. Agiza and A. A. Elsadany, "Chaotic dynamics in nonlinear duopoly game with heterogeneous players," Applied Mathematics and Computation, vol. 149, no. 3, pp. 843-860, 2004.
[3] Y. Li, Z.-H. Sheng, and G.-H. Chen, "The influence of the delayed decision on the dynamical evolution of a production system," Chinese Journal of Management Science, vol. 12, no. 2, pp. 118-123, 2004.

[4] J. Ma and Z. Guo, "The parameter basin and complex of dynamic game with estimation and two-stage consideration," Applied Mathematics and Computation, vol. 248, pp. 131-142, 2014.

[5] Z. Sun and J. Ma, "Complexity of triopoly price game in Chinese cold rolled steel market," Nonlinear Dynamics, vol. 67, no. 3, pp. 2001-2008, 2012.

[6] J. Zhang and J. Ma, "Research on the price game model for four oligarchs with different decision rules and its chaos control," Nonlinear Dynamics, vol. 70, no. 1, pp. 323-334, 2012.

[7] F. Chen, J. H. Ma, and X. Q. Chen, "The study of dynamic process of the triopoly games in Chinese $3 \mathrm{G}$ telecommunication market," Chaos, Solitons \& Fractals, vol. 42, no. 3, pp. 1542-1551, 2009.

[8] H.-X. Yao and F. Xu, "Complex dynamics analysis for a duopoly advertising model with nonlinear cost," Applied Mathematics and Computation, vol. 180, no. 1, pp. 134-145, 2006.

[9] J. Ma and X. Pu, "The research on cournot-bertrand duopoly model with heterogeneous goods and its complex characteristics," Nonlinear Dynamics, vol. 72, no. 4, pp. 895-903, 2013.

[10] H. Wang and J. Ma, "Complexity analysis of a CournotBertrand duopoly game model with limited information," Discrete Dynamics in Nature and Society, vol. 2013, Article ID 287371, 6 pages, 2013.

[11] G. I. Bischi and A. Naimzada, "Global analysis of a dynamic duopoly game with bounded rationality," in Advances in Dynamic Games and Applications, vol. 5, pp. 361-385, Springer, 2000.

[12] L. Fanti, L. Gori, C. Mammana, and E. Michetti, “The dynamics of a Bertrand duopoly with differentiated products: synchronization, intermittency and global dynamics," Chaos, Solitons \& Fractals, vol. 52, no. 1, pp. 73-86, 2013.

[13] N. Matsubayashi, "Price and quality competition: the effect of differentiation and vertical integration," European Journal of Operational Research, vol. 180, no. 2, pp. 907-921, 2007. 
[14] N. Matsubayashi and Y. Yamada, "A note on price and quality competition between asymmetric firms," European Journal of Operational Research, vol. 187, no. 2, pp. 571-581, 2008.

[15] L. Qian, "Market-based supplier selection with price, delivery time, and service level dependent demand," International Journal of Production Economics, vol. 147, no. C, pp. 697-706, 2014.

[16] A. Dubovik and M. C. Janssen, "Oligopolistic competition in price and quality," Games and Economic Behavior, vol. 75, no. 1, pp. 120-138, 2012.

[17] J. E. Stiglitz, "The causes and consequences of the dependence of quality on price," Journal of Economic Literature, vol. 25, no. 1, pp. 1-48, 1987.

[18] K. Bagwell and M. H. Riordan, "High and declining prices signal product quality," The American Economic Review, vol. 81, no. 1, pp. 224-239, 1991.

[19] H. Kebriaei and A. Rahimi-Kian, "On the stability of quadratic dynamics in discrete time $n$-player Cournot games," Automatica, vol. 48, no. 6, pp. 1182-1189, 2012.

[20] E. M. Elabbasy, H. N. Agiza, and A. A. Elsadany, "Analysis of nonlinear triopoly game with heterogeneous players," Computers and Mathematics with Applications, vol. 57, no. 3, pp. 488499, 2009.

[21] H. Kamalinejad, V. J. Majd, H. Kebriaei, and A. RahimiKian, "Cournot games with linear regression expectations in oligopolistic markets," Mathematics and Computers in Simulation, vol. 80, no. 9, pp. 1874-1885, 2010.

[22] A. A. Elsadany, H. N. Agiza, and E. M. Elabbasy, "Complex dynamics and chaos control of heterogeneous quadropoly game," Applied Mathematics and Computation, vol. 219, no. 24, pp. 11110-11118, 2013.

[23] Z. Ding, Q. Hang, and L. Tian, "Analysis of the dynamics of Cournot team-game with heterogeneous players," Applied Mathematics and Computation, vol. 215, no. 3, pp. 1098-1105, 2009.

[24] T. Li and J. Ma, "Complexity analysis of the dual-channel supply chain model with delay decision," Nonlinear Dynamics, vol. 78, no. 4, pp. 2617-2626, 2014.

[25] Y. Engel, S. Mannor, and R. Meir, “The kernel recursive leastsquares algorithm," IEEE Transactions on Signal Processing, vol. 52, no. 8, pp. 2275-2285, 2004. 


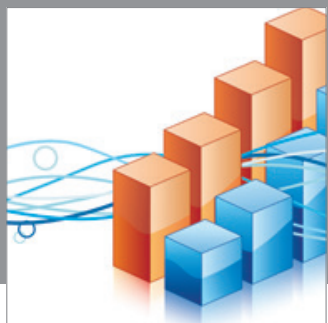

Advances in

Operations Research

mansans

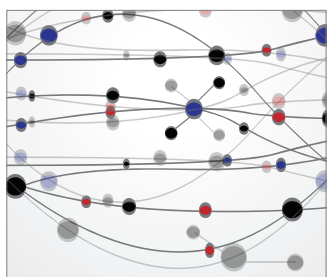

The Scientific World Journal
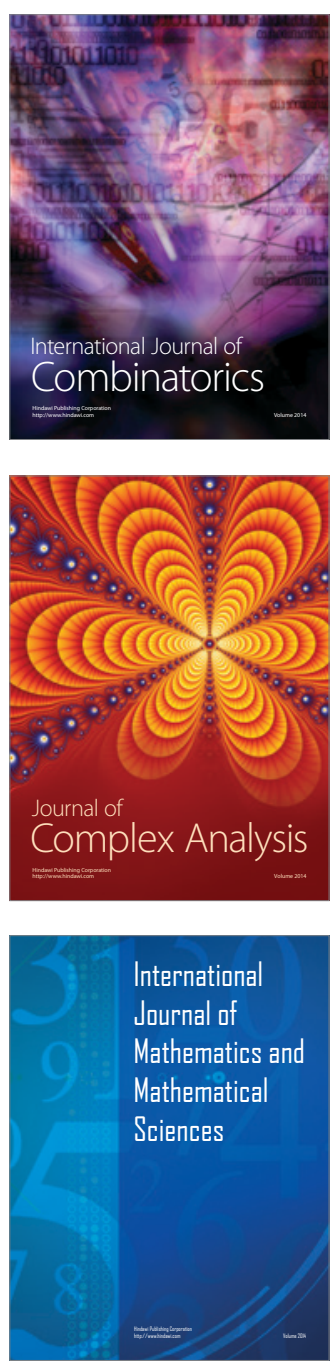
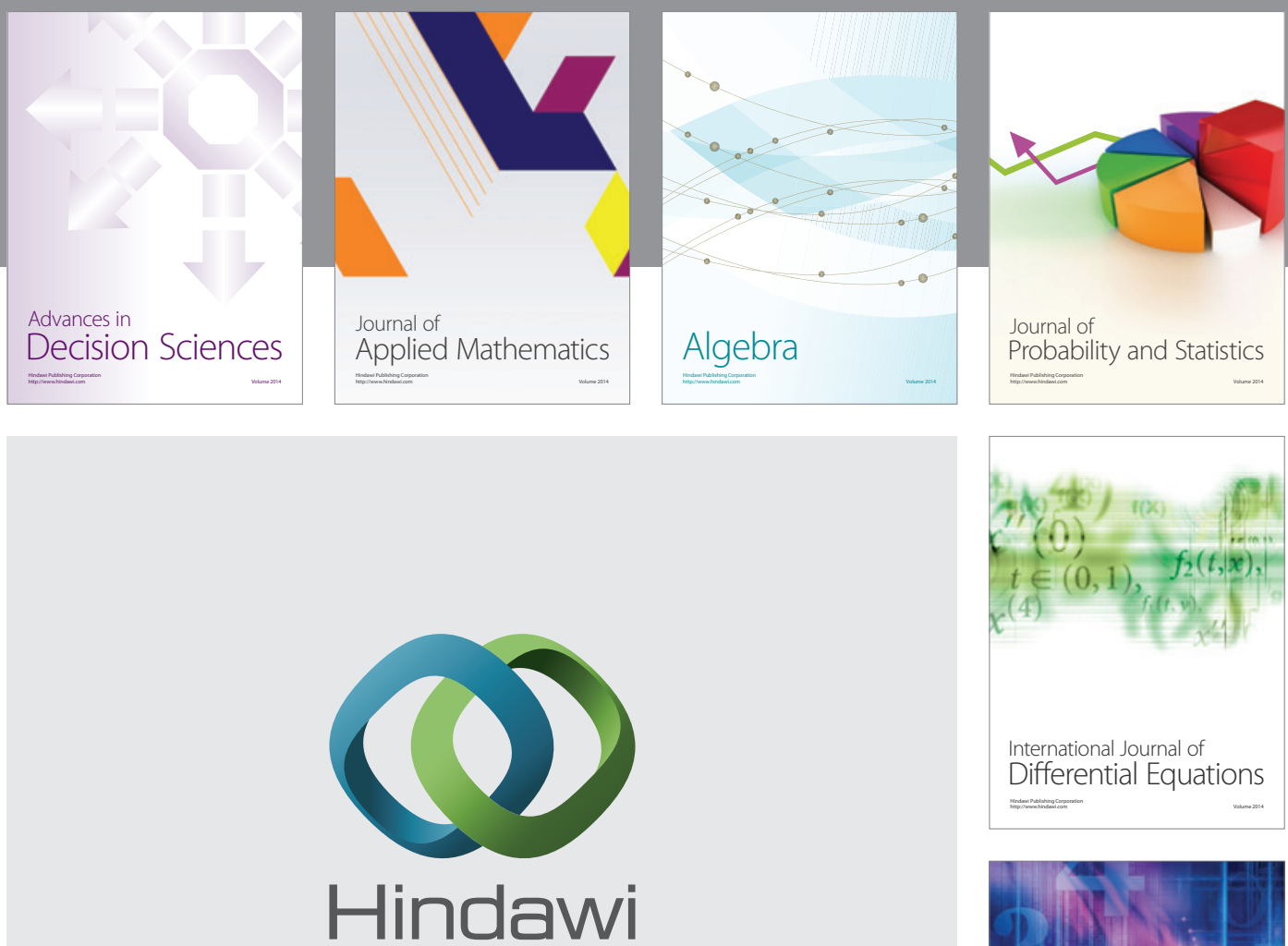

Submit your manuscripts at http://www.hindawi.com
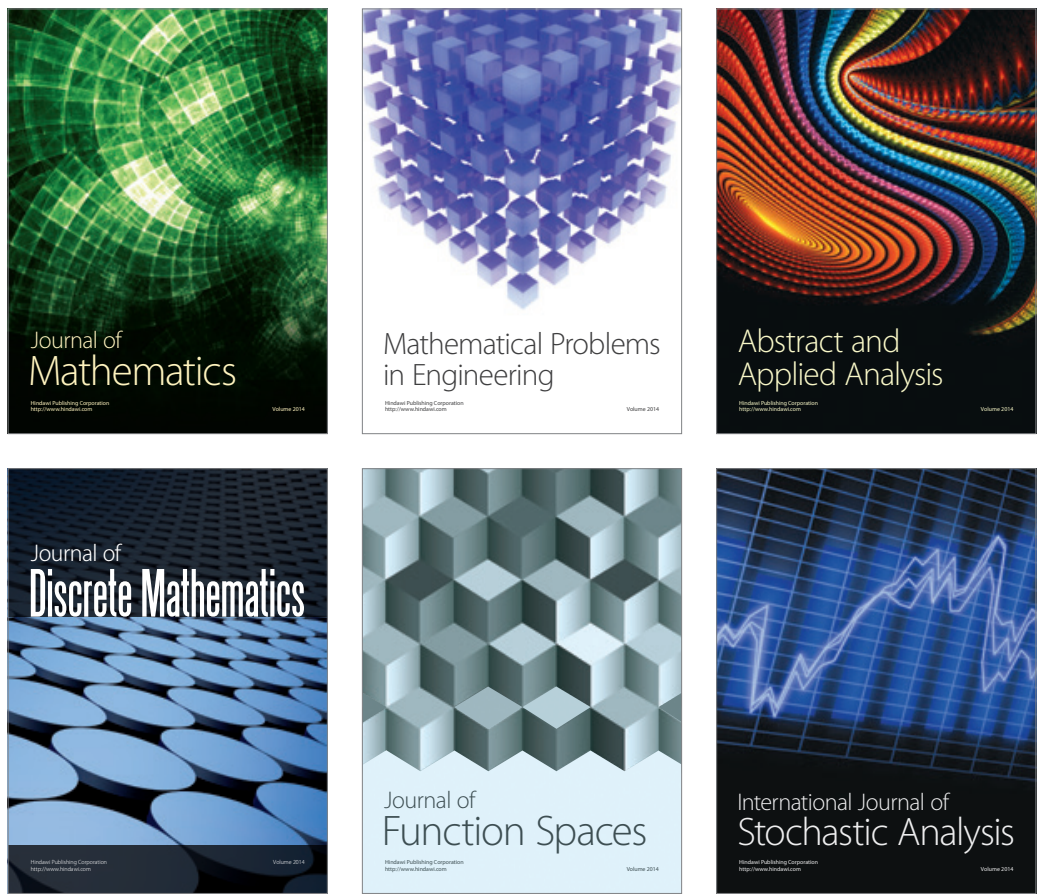

Journal of

Function Spaces

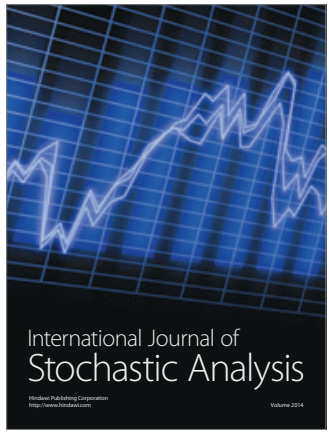

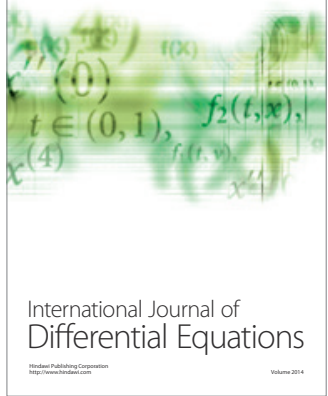
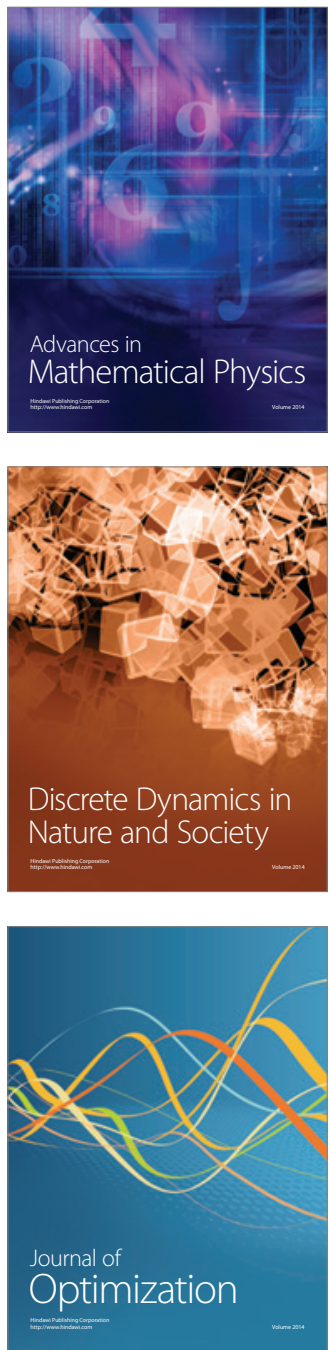